\title{
No Landward Retreat: Examining 80 years of population migration and shoreline change in Louisiana *
}

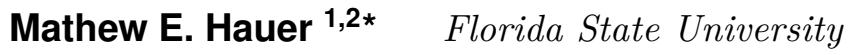 \\ R. Dean Hardy $\mathbf{2}^{\mathbf{2} 3}$ University of Maryland College Park \\ Deepak R. Mishra ${ }^{2}$ University of Georgia \\ J. Scott Pippin ${ }^{4} \quad$ University of Georgia
}

Louisiana has lost nearly 5,000 sq $\mathrm{km}$ of its coastal land area due to relative sea level rise and other factors driving local and regional sea level changes since 1932, mirroring both the hazards associated with sea level rise and the time horizons of sea level rise impacts expected this century. This represents an opportunity to examine the relationship between long-term population changes and shoreline change. Based on detailed land change data for the period 1932-2010 and a small area population estimation technique for the period 19402010, we examine intra-parish population changes in relation to shoreline changes for the one million plus residents living in the ten coastal parishes of Louisiana. We find that since 1940, only two of the ten coastal parishes exhibited landward population movement, which we define as movement perpendicular to the shoreline, exceeding $1 \mathrm{~km}$ and three parishes exhibited seaward population movement in excess of $1 \mathrm{~km}$. Overall, we find very little net intra-parish landward population movement for the region and our findings suggest that coastal Louisiana's historical population has not moved in concert with observed shoreline encroachment. We also find a potential tipping point of abandonment when a neighborhood loses $50 \%$ of its land area. Our findings suggest that this lack of landward population movement could be attributable to either localized adaptation strategies or migrations to other landward areas.

Keywords: Louisiana, Hurricane Katrina, Sea Level Rise, Adaptation, Migration, Coastal Populations, Landward Migration

*Corresponding author. mehauer@fsu.edu p: 850-644-7103.

${ }^{1}$ Department of Sociology, Florida State University. 113 Collegiate Loop. Tallahassee,

FL 32306

2 Department of Geography, University of Georgia. 210 Field St. Athens, GA USA 30602.

${ }^{3}$ National Socio-Environmental Synthesis Center, University of Maryland College Park.

1 Park Place, Annapolis MD USA 21401.

4 Carl Vinson Institute of Government, University of Georgia. 201 N. Milledge Ave. Athens, GA USA 30602.

\footnotetext{
${ }^{*}$ The data and code that supports this analysis are available in the supplementary materials.
} 
Acknowledgements: The authors would like to thank S. Holloway, J.M. Shepard, J. Rice, J. DeWaard, and J. Evans for their helpful comments. Support for RDH was provided through a Postdoctoral Fellowship with the National Socio-Environmental Synthesis Center (NSF Award \#DBI-1052875).

\section{Introduction}

Estimates of the population that could be affected by $21^{\text {st }}$ century sea level rise (SLR) range from 187 million (Nicholls et al., 2011) to over 1 billion people (Neumann et al., 2015) making SLR a major impact of climate change. Twentieth century examples of abandonment, retreat, and/or relocation due to land loss in coastal regions have already occurred (Connell, 1990; Gibbons and Nicholls, 2006; Steel, 2011) and may offer insights into the potential future experiences of populations that would be displaced by future SLR. Examining these historical analogs is key to avoiding a "no-analog future" (Fox, 2007) due to climate change impacts and to guiding the development of cohesive, effective public policy.

Hypotheses regarding population migration due to SLR undertaken in the absence of governmental intervention suggest incremental landward (defined as movement away from the shoreline) migration to nearby destinations. Döös (Döös, 1997) and Kahn (Kahn, 2014) hypothesize that SLR will spur migration toward landward areas. Curtis and Schneider (Curtis and Schneider, 2011) and Hauer (Hauer, 2017) hypothesize that SLR in the United States will likely spur migration that crosses administrative boundaries toward more landward counties (or parishes in the case of Louisiana), though not limited to just landward counties. It is possible some people may make more local moves toward higher ground or toward more landward locales within their present county. Despite these well formed hypotheses, little if any empirical work has examined population movements in relation to shoreline changes due to SLR in mainland communities.

Three widely cited examples of island abandonment in the 20th century, Holland Island, St. Kilda Island, and the Carteret Islands (Connell, 1990; Gibbons and Nicholls, 2006; Steel, 
2011), form the backbone for understanding retreat from SLR for island communities. However, these are poor analogs for understanding the potential retreat of mainland communities for several reasons. Mainland communities have additional retreat options unavailable to island communities, such as landward retreat with the shoreline (Döös, 1997). Additionally, conventional wisdom suggests that abandonment must occur if adaptive measures are not undertaken (Döös, 1997; Nicholls et al., 2011), but only one historic precedent, Holland Island (Gibbons and Nicholls, 2006), was abandoned by choice and not facilitated with a managed retreat. Lastly, the islands are sparsely populated communities and are likely unrepresentative of the millions at risk of displacement in mainland areas (Strauss, Kulp and Levermann, 2015; Hauer, Evans and Mishra, 2016). Therefore, these examples offer little insight into the theories of landward migration discussed above, and better analogies for the current situation in U.S. coastal communities could be developed.

Between 1932 and 2010, coastal Louisiana lost 1,883 square miles (4,877 square kilometers) in land area - representing a decrease of 25 percent of the 1932 land area (Couvillion et al., 2011) - due to relative SLR. We define land loss due to relative SLR as global sea-level rise plus all other factors driving local to regional sea level changes that affect local land elevation relative to local sea level including a suite of natural and anthropogenic processes such as land loss due to oil and gas canaling, damming of the Mississippi reducing sediment loading and accretion, polar icesheet gravity fingerprints, and glacial isostatic adjustment among others (Craig, Turner and Day, 1979; Gagliano, Meyer-Arendt and Wicker, 1981; Boesch et al., 1994; Barras et al., 2003; Mitrovica, Gomez and Clark, 2009; Olea and Coleman Jr, 2013; Peltier, 2004). This land loss presents an ideal situation for exploring the relationship of coastal population movement threatened by SLR and their changing shorelines for three primary reasons. First, the land loss mirrors both the hazard associated with SLR and the time horizons of SLR impacts expected this century. Second, Louisiana's one million plus coastal residents represent a population facing widespread land loss that is orders of magnitude larger than any other historically-threatened population studied in the 
literature (Connell, 1990; Gibbons and Nicholls, 2006; Steel, 2011; Connell, 2016). Lastly, local residents' complaints to local officials on coastal land loss have historically fallen on deaf ears (Boesch et al., 1994; Boesch, 2006; Burley et al., 2007; Yusuf et al., 2016), which allows us to examine population level movement responses largely in the absence of policy interventions.

Assessing population migration patterns via small area demographic change, the ideal scale at which to investigate population responses to relative SLR in Louisiana, is difficult to quantify over time due to the problems of the modifiable areal unit problem (Cromley, Ebenstein and Hanink, 2009). The U.S. Census Bureau redraws many sub-parish and subcounty Census delineated units at each decennial census limiting analysis to larger areas with relatively stable boundaries. Additionally, the United States was not fully tracted until Census 1990, limiting historical examinations of small area demographic change to just 1990, or to the major cities tracted prior to 1990, such as New York and Chicago. This forces most demographers to focus on small area population forecasts rather than population hindcasts (Swanson, Schlottmann and Schmidt, 2010; Smith, Tayman and Swanson, 2006; Hauer, Evans and Mishra, 2016).

This paper addresses these gaps and examines the relationship between long-term shoreline change and population growth/decline patterns in coastal Louisiana as an analog for understanding population responses to relative SLR in mainland communities. We combine detailed land change data, a small area estimation technique based on the Hammer Method (Hammer et al., 2004) for the period 1940-2010, and geostatistical techniques to investigate how each coastal parishes' population has moved in response to shoreline movement caused by relative SLR. To assess population "movement", we measure the distance that each parishes' weighted mean population center has changed in decadal increments. We ask three fundamental questions relating to population movement: Has coastal Louisiana's population moved landward, which we define as perpendicular to the shoreline, corresponding with shoreline encroachment from relative SLR? What is the relationship between land 
loss and population growth/decline within neighborhoods (i.e., Census Block Groups)? and; What threshold, if any, of land loss might be associated with abandonment?

Scholars have identified the investigation of possible tipping points as important avenues of research (Bardsley and Hugo, 2010; Black, Adger, Arnell, Dercon, Geddes and Thomas, 2011; McLeman, 2011) and we contribute to this conversation with empirical analysis of population change in concert with land change in coastal Louisiana. Our analysis identifies possible thresholds related to land loss that might be associated with population declines. Additionally, knowledge of self-organized SLR retreat is important for designing appropriate policies aimed at both stemming the impacts of SLR and for the organization of managed retreats.

\section{Background}

\section{Adaptation to sea level rise}

SLR is one of the most written about and best understood implications of climate change (IPCC, 2014). Detailed research has sought to identify the specific communities at risk (Wu, Yarnal and Fisher, 2002; Martinich et al., 2013; Hauer, Evans and Alexander, 2015) and numerous scholars have provided guidance and assessments for local adaptation planning (Lutsey and Sperling, 2008; Titus et al., 2009). Recently, highly localized estimates and projections of populations at risk to SLR have been of significant interest (Lutz et al., 2007; Rowley et al., 2007; Plyer, Bonaguro and Hodges, 2010; Curtis and Schneider, 2011; Hauer, Evans and Alexander, 2015; Hardy and Hauer, 2018) and the implications of SLR-driven migration on population landscapes beyond coastal zones are starting to be understood (Hauer, 2017). The behaviors deployed to adapt to climate change have long been studied (Smit and Skinner, 2002; Berrang-Ford, Ford and Paterson, 2011), but the research surrounding the migration behaviors of mainland populations related to SLR have tended to be theoretical rather than empirical (Döös, 1997). 
Coastal residents' responses to shoreline erosion and relative SLR broadly fit three categories: shore protection, accommodation, and retreat (Titus et al., 2009; Nicholls et al., 2011). Socioeconomic and environmental conditions can dictate the response (or even a mixture of responses) employed to cope with rising seas (Gornitz, 2013). Protection primarily consists of infrastructure solutions such as dikes, levees, seawalls, and other "hard armoring" techniques or beach renourishment as "soft armoring techniques". Individuals can also employ a wide variety of adaptation techniques through accommodation. For instance, garages can replace many ground-floor spaces in homes preventing high water events from passing through more expensive to repair living areas. Florida building codes require minimum housing elevations above the crown of the road, reducing the risk of catastrophic flooding from hurricanes (Dehring, 2006). Important roads can be raised if localized flooding becomes too burdensome on local residents and businesses.

Retreat is an option for sparsely developed areas and can be undertaken when protection and accommodation are either ineffective or too costly. Managed retreats have been undertaken before, as seen on St. Kilda Island in Scotland in the 1970s (Steel, 2011), and have begun more recently for the community of Isle de Jean Charles in coastal Louisiana (Simms, 2016) ${ }^{1}$. Many people do not want to move, however, and overwhelmingly favor "holding the line" rather than relocating (Zhang, Douglas and Leatherman, 2004) (oftentimes called the "immobility paradox" (Findlay, 2011)). Retreat could be the end of a community, which people may be very reluctant to accept. The costs of retreat will vary widely, and will be borne by the property owners in an unmanaged, or ad hoc retreat, or by the public at large through a government-managed retreat with estimates for managed retreats upwards of $\$ 100,000$ to $\$ 1$ million per person (Huntington, Goodstein and Euskirchen, 2012; Hino, Field and Mach, 2017).

\footnotetext{
${ }^{1}$ These communities do not use the terms "retreat" to describe their efforts. Instead, they describe their efforts as "relocation" or "resettlement." http://isledejeancharles.la.gov/
} 


\section{Materials and Methods}

We examine coastal Louisiana's population movements in relation to observed relative SLR effects on Louisiana's shoreline by using the U.S. Geological Survey's (USGS) Land Area Changes in Louisiana data set (Couvillion et al., 2011). These data collate 17 data sets of historical surveys, airborne and satellite data, and consistent change criteria to track landscape change in Louisiana between 1932 and 2010 with land loss measured at 30-meter and 60-meter resolutions, depending on the time period. While some landlocked Louisiana parishes (governing units that are essentially equivalent to U.S. counties within the U.S. Census) experienced land loss since 1932, we consider only census block groups in parishes adjacent to the Gulf of Mexico for this analysis as the land loss in these parishes is significantly greater than in the landlocked areas. We aggregate all land loss/gain over the time period into single loss/gain categories.

\section{Coastal Louisiana}

The wetlands in coastal Louisiana comprise the seventh largest delta on Earth and are an environmentally fragile ecosystem, accounting for $90 \%$ of the coastal wetland loss in the United States (Couvillion et al., 2011) (Figure 1). Currently, Louisiana is losing $10.8 \mathrm{mi}^{2}$ $\left(28 \mathrm{~km}^{2}\right)$ per year or the equivalent of one American football field per 100 minutes (Couvillion et al., 2017).

The factors driving land loss due to relative SLR in coastal Louisiana are well-documented phenomena (Craig, Turner and Day, 1979; Burley et al., 2007; Couvillion et al., 2011). As mentioned above, a host of processes - both natural and anthropogenic - are responsible for this loss and include tropical cyclones, natural erosion from waves, dredging, building oil and gas pipeline networks, flood-control practices such as diversion canals, and local to regional patterns of SLR (Craig, Turner and Day, 1979; Burley et al., 2007); even global SLR has natural and anthropogenic processes driving it, although anthropogenic forces have 


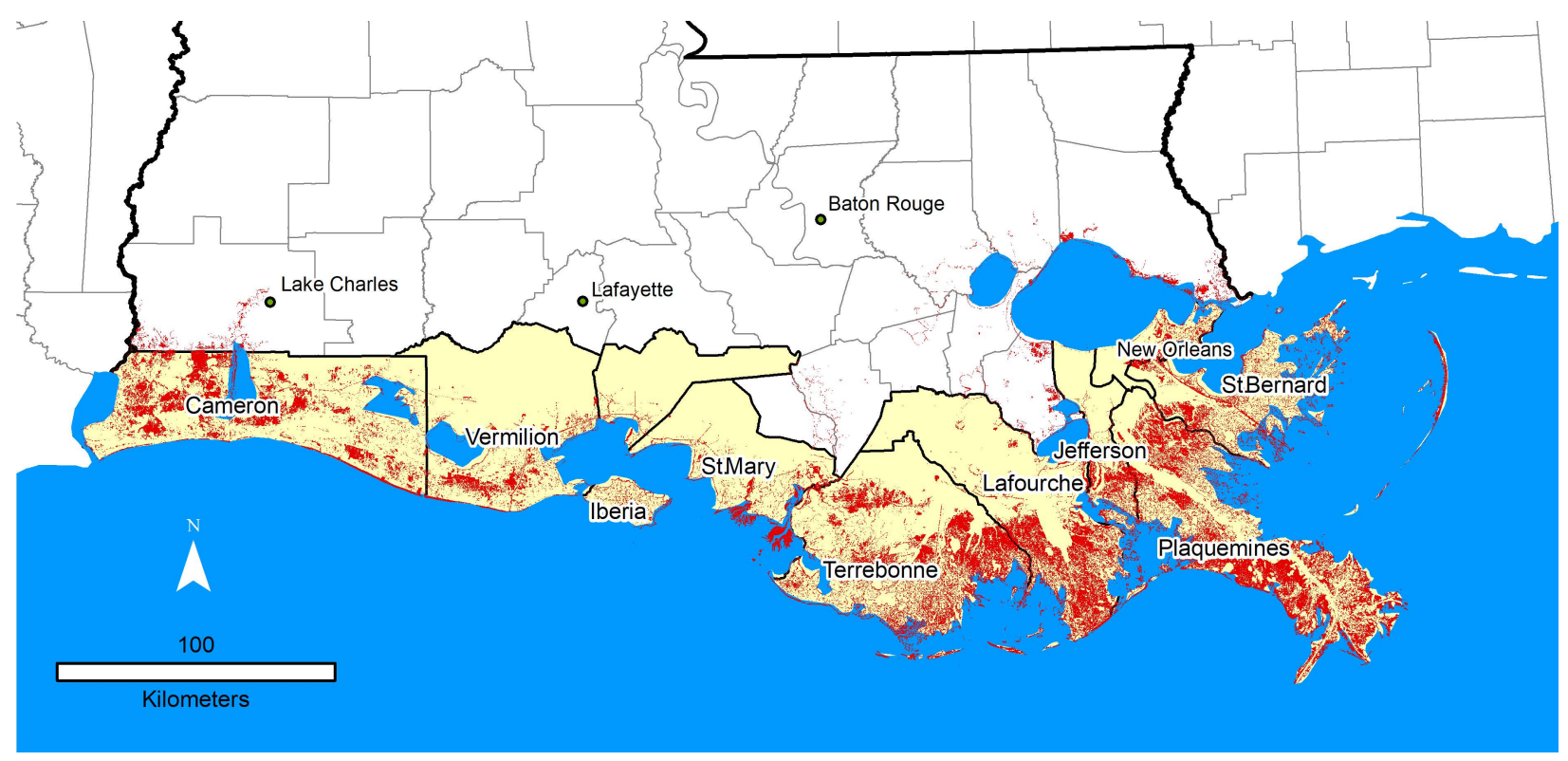

Figure 1: Study area parishes are colored in tan. Red areas indicate land loss due to relative SLR between 1932 and 2010.

dominated since the 1950s (Marcos et al., 2017). The leveeing of the Mississippi River and the fragmentation of coastal land area due to diminished sediment supply and the complicated networks of oil and gas pipelines have altered the natural accretion of sediment in the coastal area, causing much of the area to slowly sink, lose land area, and increasing vulnerability to disastrous storm surges. While research on the attribution of natural/anthropogenic forces to this land loss is important, for our purposes we make no direct distinction between natural/anthropogenic in our analysis. We are not examining the causes of the land loss but rather how these changes relate to population movements.

During the same period of observed land loss (1932-present), the population in coastal Louisiana boomed. Between 1940 and 1980 the region saw its population increase by approximately $95.0 \%$, growing from 752,651 people in 1940 to 1,465,340 in 1980. Since 1980, the population in coastal Louisiana has slowly decreased, declining from 1,465,340 in 1980 to $1,419,167$ in 2000. The effects of Hurricanes Katrina and Rita on population changes in 2005 are well known (Thiede and Brown, 2013; Curtis, Fussell and DeWaard, 2015) and are a contributing factor to the population decline in the region after 1980 . 
With $70+$ years of both population and land classification data, the time horizons for land loss in coastal Louisiana mirror the time horizons for projected SLR impacts in the $21^{\text {st }}$ century. Louisiana's one million plus coastal residents represent a population facing widespread land loss that is orders of magnitude larger than any other historically threatened population studied in the literature (Connell, 1990; Gibbons and Nicholls, 2006; Steel, 2011). Moreover, coastal Louisiana is one of the areas most threatened by relative SLR in the United States. Many coastal Louisiana parishes could see over $50 \%$ of their populations directly impacted by $1.8 \mathrm{~m}$ of SLR by the end of the century (Hauer, Evans and Mishra, 2016).

\section{Housing Units}

We overcame the issue of the mutability of sub-parish units to produce spatio-temporally contiguous housing estimates by using a modified Hammer Method (Hammer et al., 2004; Hauer, Evans and Mishra, 2016) to produce estimates by census block groups (CBG) for the period 1940-2010. By creating historic small area housing estimates we are able to investigate population movement within coastal parishes. Equation 1 demonstrates the modified Hammer Method for estimating the number of housing units in CBGs.

$$
\hat{H}_{i j}^{v}=\left(\frac{C_{j}^{v}}{\sum_{i=1}^{n} \sum_{t=1939}^{v-1} H_{i j t}^{v}}\right) \cdot \sum_{t=1939}^{v-1} H_{i j t}^{v}
$$

where:

$C_{j}^{v}$ is the number of HUs in parish $j$ counted in census taken in time $v$

$H_{i j}^{v}$ is the number of HUs in block group $i$ in parish $j$ based on the "year structure built" question in the U.S. Census American Community Survey (ACS)

$v$ is the set of time periods $v \in\{1940,1950,1960,1970,1980,1990,2000,2010\}$

Thus, to estimate the number of housing units in block group $i$ in parish $j$ for the year 1970, for example, the number counted in parish $j$ according to the 1970 census $\left(C_{j}^{1970}\right)$ is divided by the number of HUs in parish $j$, as estimated in the ACS, for the period 1939-1969 $\left(\sum_{i=1939}^{1969} H_{j}^{1970}\right)$ and multiplied by the number of HUs estimated in the ACS in block group $i$ 
for the same period $\left(\sum_{i=1939}^{1969} H_{i j}^{1970}\right)$. This is repeated for each decade until the most recent time period. These estimates of HUs for each CBG provide the key input needed to convert an estimate of HUs into an estimate of total population.

Data for historically estimating the housing units come from two main sources. First, the ACS 2008-2012 estimates provide the "year structure built" data as well as the 2010 boundaries for the CBGs. Second, the actual historical count of populations and housing units for each parish come from digitized records available on the Census Bureau's website. ${ }^{2}$ By creating historic small area population estimates we are able to investigate population movement within coastal parishes.

\section{Housing Units to Population}

To estimate population at time $t\left(P_{t}\right)$, Equation 2 is applied to convert an estimate of HUs to an estimate of population.

$$
P_{t}=H \cdot P P H U
$$

Where $H$ is the number of housing units and $P P H U$ is the persons per housing unit. The two variables required to calculate the PPHU are known only for each historical census at the parish level, thus the $P P H U$ for each CBG must be estimated. Keeping in the same tradition as Hammer, we utilize the known variability in current decadal CBG geography for PPHU to backcast PPHU for prior decades based on this variability using a doublerake proportional fitting algorithm (Deming and Stephan, 1940). The first rake occurs by proportionally adjusting each CBG's PPHU value and the second rake occurs by ensuring the sum of the CBG populations equal the parish's historical count of population.

Equation 3 demonstrates the historical calculations of population for each CBG for any given time period.

\footnotetext{
${ }^{2}$ For 1940 to 1990, data can be found at http://www.census.gov/prod/cen1990/cph2/cph-2-1-1.pdf. Census 2000 data can be downloaded through American FactFinder.
} 


$$
P_{i j}^{\prime v}=\frac{P_{j}^{v}}{\sum\left[\left(\frac{P P H U_{i j}^{2010}}{P P H U_{j}^{2010}} \cdot P P H U_{j}^{v}\right) \cdot \hat{H}_{i j}^{v}\right]} \cdot \hat{P}_{i j}^{v}
$$

The PPHU in CBG $i$ in parish $j$ in 2010 is denoted as PPHU $U_{i j}^{2010}$ while the PPHU observed in parish $j$ in historical time $v$ is denoted as $P P H U_{j}^{v}$. The initial $P P H U$ estimate for each CBG is computed as the ratio of the PPHU in CBG $i$ in parish $j$ in 2010 to the PPHU in parish $j$ in 2010 multiplied by the observed PPHU in parish $j$ in historical time period $v$. This initial estimate of historical PPHUs are then multiplied by the estimated number of Housing Units as estimated from Equation $1\left(\hat{H}_{i j}^{v}\right)$ in historical time $v$ to create an initial estimate of population. These are then summed to the parish level and proportionally adjusted based on the observed population of a parish from historical time period $v$. By simply dividing the estimated population by the estimated number of housing units, we will generate $P P H U$ for any given time period $\left(P_{i j}^{\prime v} / \hat{H}_{i j}^{v}\right)$. This provides us with variable $P P H U$ estimates for each CBG for each time period in any given parish. This makes it possible to produce a historical time series of population and housing units at the CBG geography with consistent boundaries for a period of 1940-2010 and with unique PPHU values for each time period.

To estimate the historical population in block group $i$ in parish $j$ in time 1970, for example, one would first divide $P P H U_{i j}^{2010}$ by $P P H U_{j}^{2010}$ and then multiply by the PPHU in parish $j$ in historical time $v\left(P P H U_{j}^{1970}\right)$. In essence, this creates a raked $P P H U$ value in historical time $v$. This raked PPHU value is then multiplied by the output from the Equation $1\left(\hat{H}_{i j}^{1970}\right)$, and summed to parish $j$. This creates an estimated population in time $v$ that is raked a second time $\left(P_{j}^{1970} / \hat{P}_{j}^{1970}\right)$ and multiplied by the estimated population in each member block group $\left(\hat{P}_{i j}^{1970}\right)$.

\section{Limitations}

There are several limitations in using these approaches that we acknowledge. These limitations include (i) assumptions that the relative distribution of housing in each year-built 
period (ie, 1939-1970) represents the actual proportional allocation of housing in that period. For example, if block group $i$ contains 10\% of the housing units built between 1939 and 1970 in parish $j$, as observed in the ACS, Hammer's method assumes that block group contains $10 \%$ of the counted housing units from Census 1970. And (ii) the methods rely heavily on the accuracy of the reported age distribution (year structure built) of the housing stock. Errors due to misreporting or age heaping can significantly impact the results. Additionally, the method we ouline above relies on relatively low "churn" of the housing stock. Any homes that are destroyed and rebuilt will bias estimates toward more recently built structures.

Despite these limitations, previous research supports our methodological approach. First, regarding the appropriateness of proportional fitting to small-area demographic analysis limitation (i) - scholars have successfully employed proportional fitting methods to subcounty and sub-parish geographies with great success for a number of years (Beckman, Baggerly and McKay, 1996) with Wong (Wong, 1992) even encouraging their use for small area geographic analysis. Evaluations of the errors associated with proportional fit estimates of Census Tracts and CBGs demonstrate consistently low errors (Wong, 1992; Beckman, Baggerly and McKay, 1996; Choupani and Mamdoohi, 2016; Rose and Nagle, 2017) giving us confidence in the quality of our own sub-parish proportionally fit historical estimates. The more recent evaluations of sub-county and sub-parish proportional fitting utilize ACS data the same data source we use - finding acceptably low errors. Second, regarding low "churn" of the housing stock - limitation (ii) - it is possible that the devestating hurricanes that hit Louisiana over the past few decades could cause our estimates to be biased toward more recently built structures. However, the proportional fitting approach ensures that sub-parish housing unit estimates always sum to the observed housing units in the historical period. Thus, only if the "churn" occurs in a significantly uneven geographic pattern should this be a concern. While this is possible, we believe it unlikely in light of the stability of our results below. 


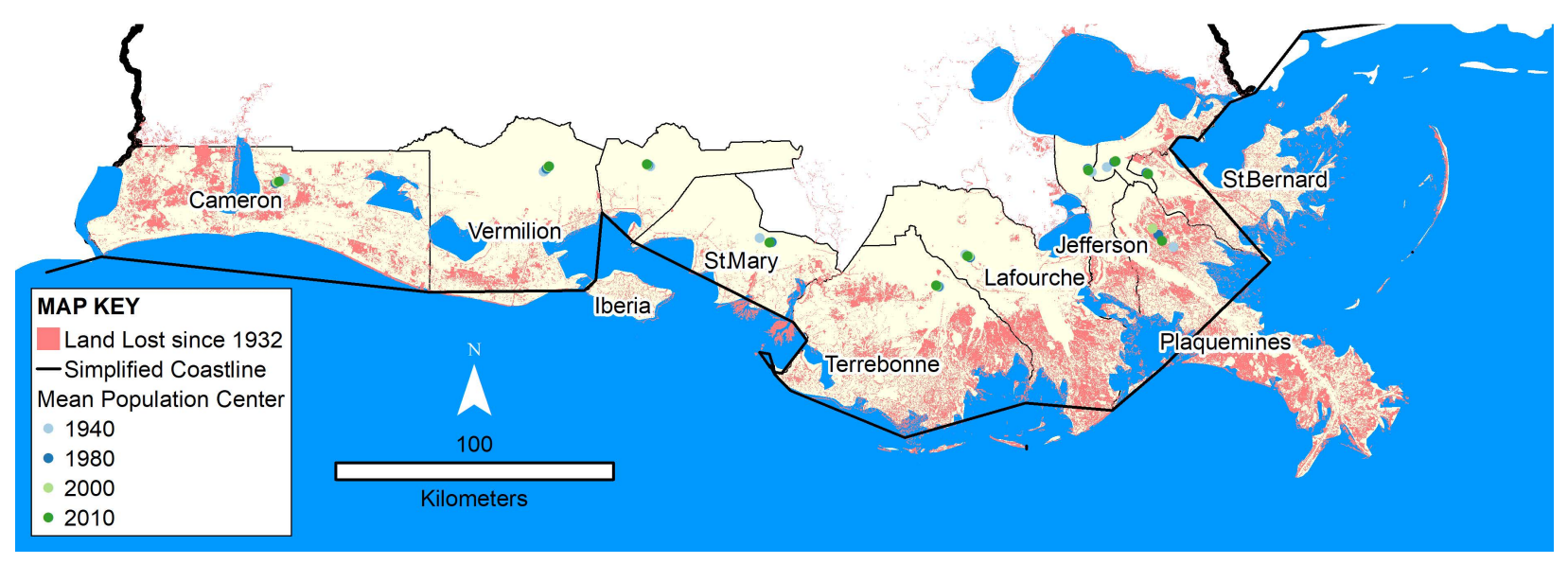

Figure 2: Land Loss Due to Relative SLR and Population Movement for Coastal Louisiana, 1940-2010. Areas in red indicate land lost since 1932. The mean population centers for 1940, 1980, 2000, and 2010 are also included.

\section{Measuring Population Movement}

Population in a given CBG or parish could continue to grow while the land area is shrinking. We measure population movement by using a geostatisical approach consisting of two steps. First, to determine if a parish experienced movement of its population, we employ the use of a weighted mean-center of the population, given as the weighted average of the $x$ and $y$ centroid coordinates of all of the block groups in a parish. Here, our weight is given as the total population of a block group for each decade between 1940 and 2010. With a 2010 mean population center as our starting point, movement of the population is measured as a shift in the mean center relative to the shoreline. Positive distances, or distances that increase, are defined as more landward movement while negative distances, or distances that decrease, are defined as more seaward movement. The weighted mean center is given as:

$$
\bar{X}_{w}=\frac{\sum_{i=1}^{n} w_{i} x_{i}}{\sum_{i=1}^{n} w_{i}}, \frac{\sum_{i=1}^{n} w_{i} x_{i}}{\sum_{i=1}^{n} w_{i}}
$$

To measure landward movement of the population relative to the coastline, we first simplify the US coastline using the simplify_shape function from the tmaptools package in R. 
simplify_shape uses the Visvalingam algorithm to modify the area metric by underweighting the effective area of points at the vertex of more acute angles. This step is undertaken to remove extemporaneous abutments present in the Louisiana coastline (Figure 2). Next, we determine the Euclidean distance from each mean center in each time period to each parish's nearest simplified coastline.

\section{Results}

The ten-parish region saw its population increase by 483,575 persons between 1940 and 2010 while simultaneously losing approximately 4,000 square kilometers of land area due to relative SLR (Table 2). Thus, coastal Louisiana continued to see population growth despite nearly unprecedented land loss over time horizons mirroring those predicted for SLR in the 21st century.

Has coastal Louisiana's population moved landward, corresponding with shoreline changes from relative SLR?

Overall, we observe no robust landward population movement in eight of the ten coastal parishes with only Jefferson and Terrebonne parishes exhibiting landward movement in excess of $1 \mathrm{~km}$ (Figure 3 and Figure 2). Three coastal parishes exhibited seaward movement in excess of $1 \mathrm{~km}$ between 1940 and 2010 - Cameron, Orleans, and St. Bernard (Figure 2). These parishes have population movements that draw the population center closer to the encroaching shoreline. For the region as a whole, the mean centers were approximately 31.5 $\mathrm{km}$ from the shoreline in 1940 and were $30.6 \mathrm{~km}$ from the shoreline in 2010 - demonstrating no substantial landward movement across the aggregated study region.

Plaquemines Parish observed the greatest landward population movement between 1940 and 2000, moving nearly $10 \mathrm{~km}$ landward in conjunction with experiencing the greatest land loss due to relative SLR in coastal Louisiana. However, between 2000 and 2010, Plaquemines Parish's population center moved over $10 \mathrm{~km}$ seaward representing a rapid and dramatic 


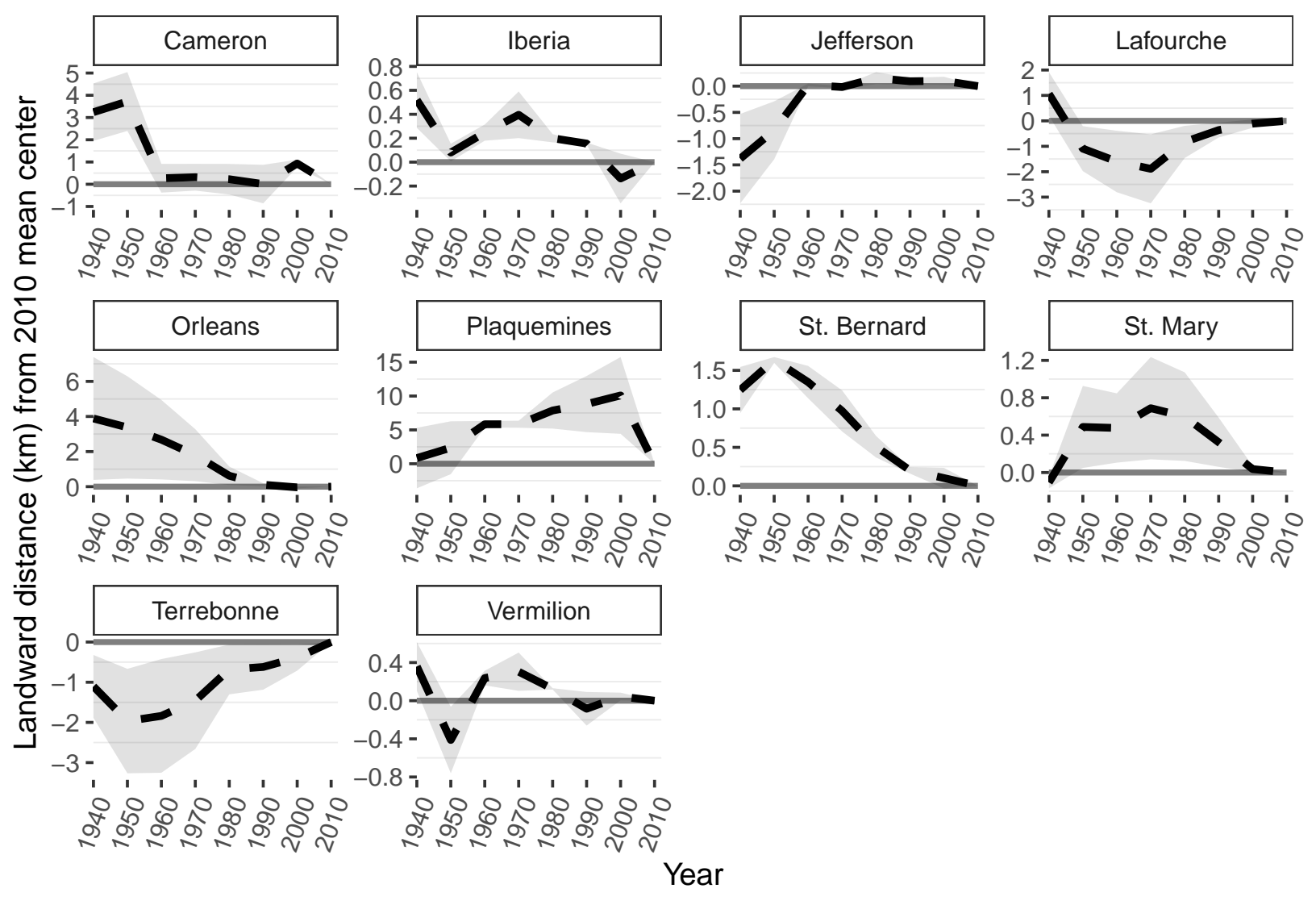

Figure 3: Distance in kilometers from the 2010 mean center population for Coastal Louisiana parishes, 1940-2010. Positive distances or distances that increase reflect landward population movement, negative distances or distances that decrease reflect seaward population movement. The shaded area is the $90 \%$ confidence interval. Lines below the 0 line indicate a mean center that is more seaward of the 2010 mean center while lines above the 0 line indicate a mean center that is more landward of the 2010 mean center. For example, Cameron Parish's 1940 mean center is approximately $3 \mathrm{~km}$ more landward than the 2010 mean center, suggesting seaward movement of Cameron's housing stock. 


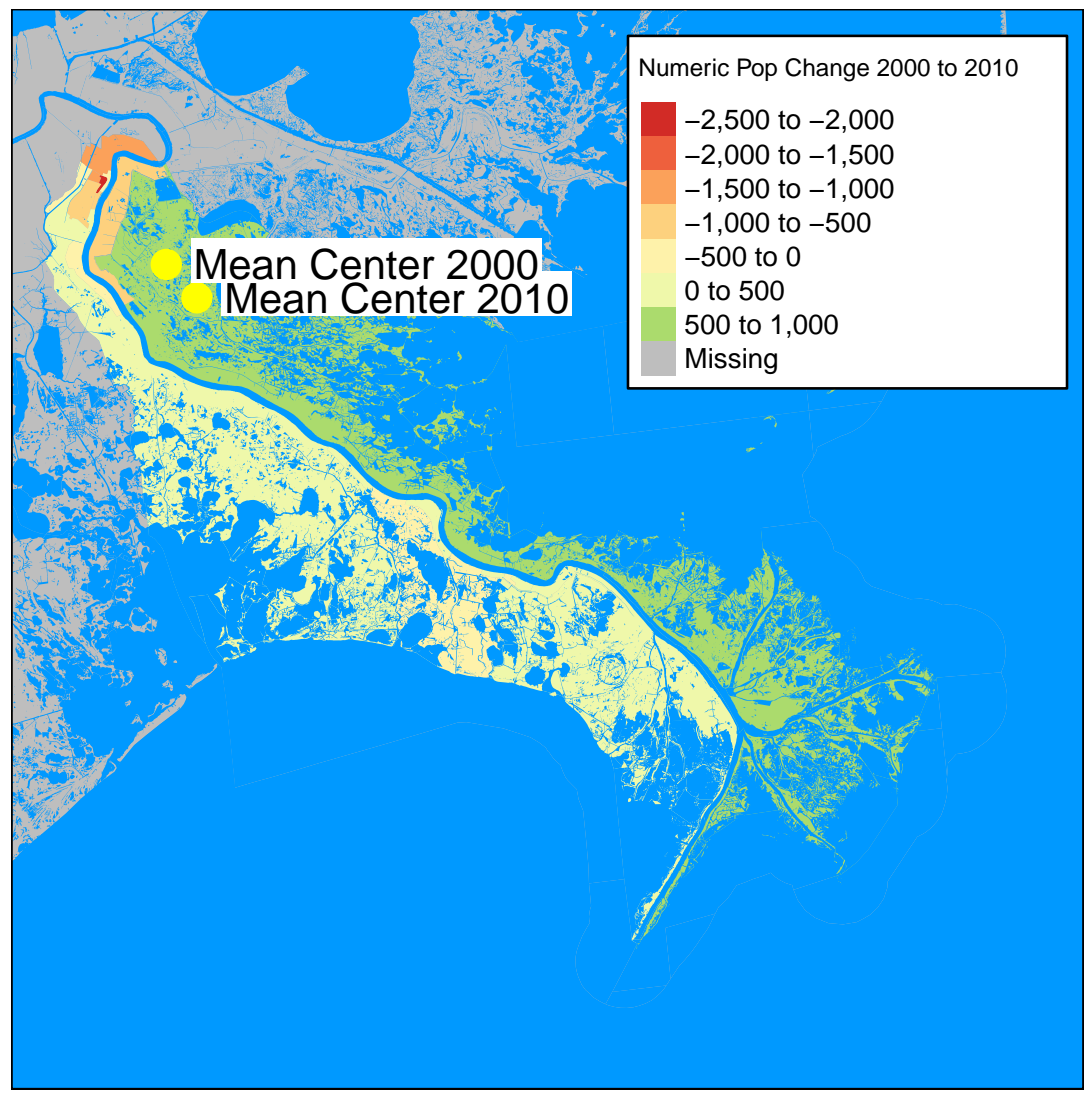

Figure 4: Population Change in Plaquemines Parish, 2000-2010. The declining populations in the northern part of the parish and the population growth in the southern part led to the seaward movement of the mean population center.

shift in its population coinciding with the extraordinary, and well-documented, demographic changes caused by Hurricanes Katrina and Rita through population displacement (Sastry, 2009; Hori, Schafer and Bowman, 2009; Gutmann and Field, 2010).

Landward population movement is present in Plaquemines Parish, however, with the parish experiencing the greatest relative SLR. Other parish populations could also move landward as their communities continue to subside. Jefferson, Terrebonne, and Vermilion parishes exhibit much smaller landward movements, but may increasingly move landward as relative SLR continues. 
What is the relationship between land loss and population growth/decline?

Approximately one-third of CBGs experiencing land loss also experienced population decline since 1980 (58 out of 161) meaning that nearly two-thirds of CBGs that are losing land area grew in population (Table 1). The relationship is inverted for the CBGs that did not experience land loss, where nearly $75 \%$ of the CBGs experiencing no land loss declined (753 out of 1024). Over $90 \%$ of CBGs experiencing population declines since 1980 did not experience land loss (753 out of 811).

What threshold, if any, of land loss leads to abandonment?

We observe a relatively strong relationship between land loss and population decline since 1980 as land loss increases (Figure 5 and Table 2). In all CBGs experiencing land loss ( $\mathrm{n}=$ 161), approximately $30 \%$ also experienced population declines. As the amount of land loss experienced in a CBG increased the likelihood of a CBG experiencing decline also increased. Half of the CBGs that experience greater than $50 \%$ land loss also went into population decline, rising to $60 \%$ of these CBGs when over $55 \%$ of the land area disappeared.

Taken together, these results suggest a possible "tipping point" near $50 \%$ of land loss before the majority of CBGs go into population decline. It bears repeating that population decline could be tied to numerous other effects aside from relative sea level rise and shoreline retreat, but these results demonstrate a potential relationship.

\section{Discussion}

Coastal populations will face increasing threats from climate change in the coming decades and beyond. Our empirical work offers a quantitative examination of population movement in relation to relative SLR, or long-term, slow onset environmental change in mainland areas. We observe very little landward population movement, in opposition to hypothesized migration responses (Döös, 1997) and rational "self-preservation" models (Kahn, 2014). 


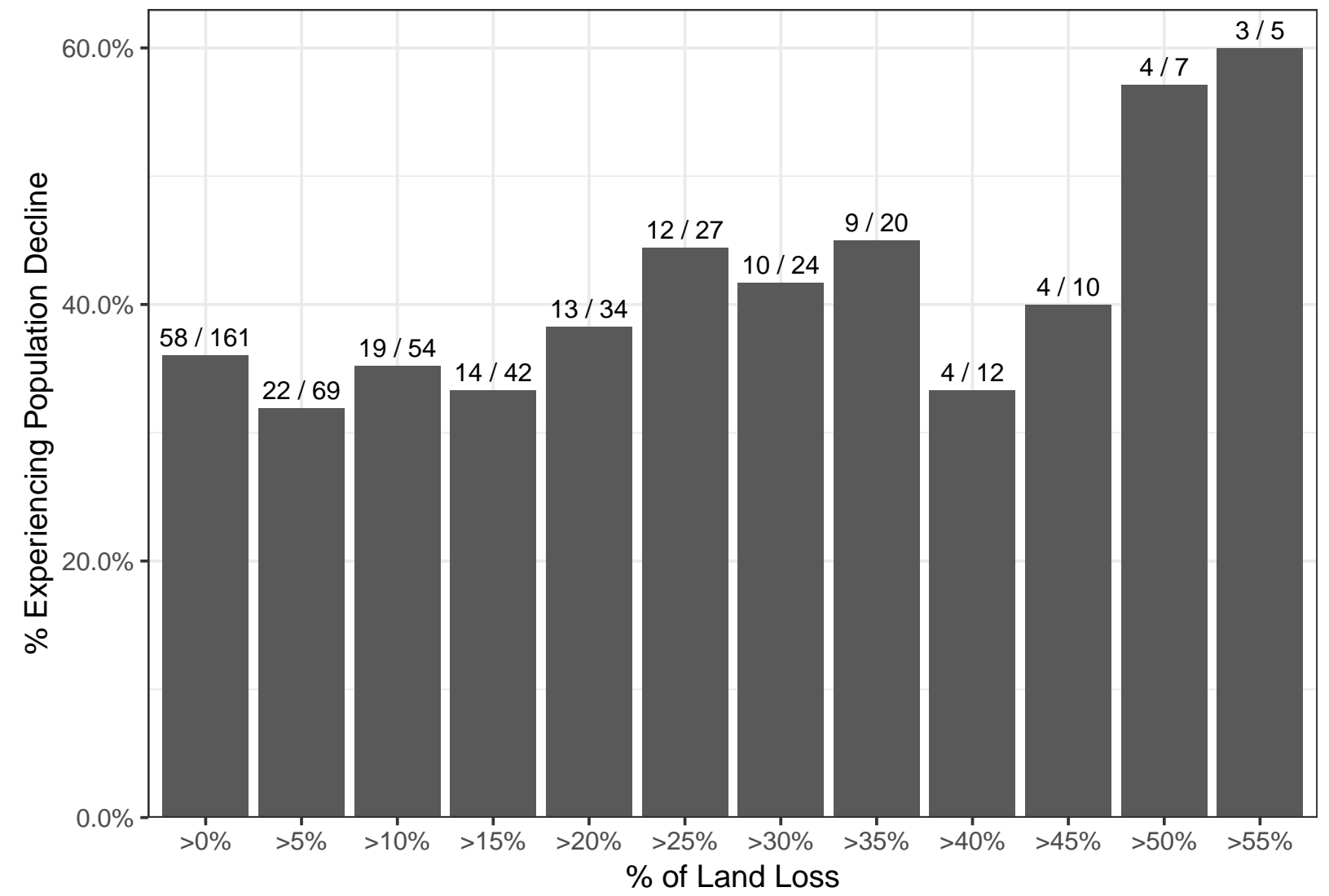

Figure 5: Percent of block groups experiencing population declines between 1980 and 2010 by the amount of land loss since 1940. The numbers above the bars reflect the number experiencing decline and the number of block groups in that land loss category. 
The lack of landward population movement coupled with continued population growth suggests two possible options. First, in-situ adaptation is likely occurring due to the "immobility paradox" (Findlay, 2011). Retreat is typically the last option, as people will adjust their behavior before they adjust their location. Migration is costly in terms of financial and social capital and deep rooted cultural ties. Our results suggest that the population in coastal Louisiana is not moving landward and, considering our results in conjunction with relative population stability, residents appear to favor "holding the line", echoing many findings in the literature of other communities facing environmental migration pressures (Zhang, Douglas and Leatherman, 2004; Findlay, 2011; Maldonado, 2015). Accommodation efforts have been employed in Louisiana for decades and include voluntary home elevation, deployment of floating docks, and a replacement of older structures with more resilient ones (Bailey, Gramling and Laska, 2014). However, when people do choose to stay, they face increased risks to health and safety (Maldonado et al., 2013), and could ultimately require additional measures to address increasing vulnerability (Black, Adger, Arnell, Dercon, Geddes and Thomas, 2011).

Historical small area population data is virtually non-existent in the United States as the U.S. Census Bureau completely tracted the United States only in 1990. To overcome this issue, we applied a novel method of population estimation. The absence of sub-parish population data makes it impossible to determine the accuracy of these estimates, but previous assessments of similar methods have proved quite accurate (Hauer, Evans and Alexander, 2015; Hauer, Evans and Mishra, 2016). The lack of substantial landward population movement in some parishes could be methodologically driven rather than empirically driven. Landward population movement could have occurred within block groups rather than between block groups, but with little to no historical data, geographies smaller than block groups are virtually impossible to examine at this scale. Despite these limitations, we believe our analysis accurately describes the historical population distribution and mean population movements of the parishes in coastal Louisiana. 
Additionally, we only investigate population movement within coastal parishes. Landward retreat via out-migration to more distant, landlocked communities is still possible, similar to the population redistribution that occurred after Hurricanes Katrina and Rita (Hori, Schafer and Bowman, 2009; Curtis, Fussell and DeWaard, 2015). Although we did not examine such historical migration destinations due to the very limited linked historical origin-destination migration data that exists in the United States, the findings from our study provide an insight into the population movements in Louisiana's coastal parishes in relation to relative SLR. The mechanisms behind environmental migration could be tied to other effects of relative SLR such as economic losses, changes in fisheries, or damage to infrastructure (Black, Adger, Arnell, Dercon, Geddes and Thomas, 2011) or reasons completely unrelated to environmental change. It might not be direct impacts from shoreline retreat that lead to landward population movement, but rather a combination of direct and associated effects - effects long noted in the environmental migration literature (Black, Adger, Arnell, Dercon, Geddes and Thomas, 2011; Black, Bennett, Thomas and Beddington, 2011).

The approach we demonstrate in this paper allows for investigations of historical small area demographic changes in relation to gradual environmental changes caused by a changing climate. We believe that the coupling of historical small area estimates with other climaterelated hazards such as droughts or changing precipitation regimes to jointly investigate climate change analogs and demographic change is a fruitful approach for future research.

\section{Data availability}

All data generated and analyzed and all $\mathrm{R}$ code needed to replicate these results are available in the supplementary material.

\section{Ethical Standards}

All experiments comply with ethical standards in the United States. 
Table 1: Land and population loss in coastal Louisiana, 1980-2010 by Census Block Group. CBGs without land area were excluded from the land loss/no land loss/decline/no decline categories.

\begin{tabular}{lllll}
\hline & Land Loss & No Land Loss & TOTAL \\
\hline Pop. Decline & 58 & 753 & 811 \\
& $36 \%$ & & $73.5 \%$ & \\
& & & & \\
No Pop. Decline & 103 & & 271 & \\
\cline { 5 - 6 } & $64 \%$ & & $26.5 \%$ & \\
TOTAL & 161 & & 1024 & \\
\hline
\end{tabular}




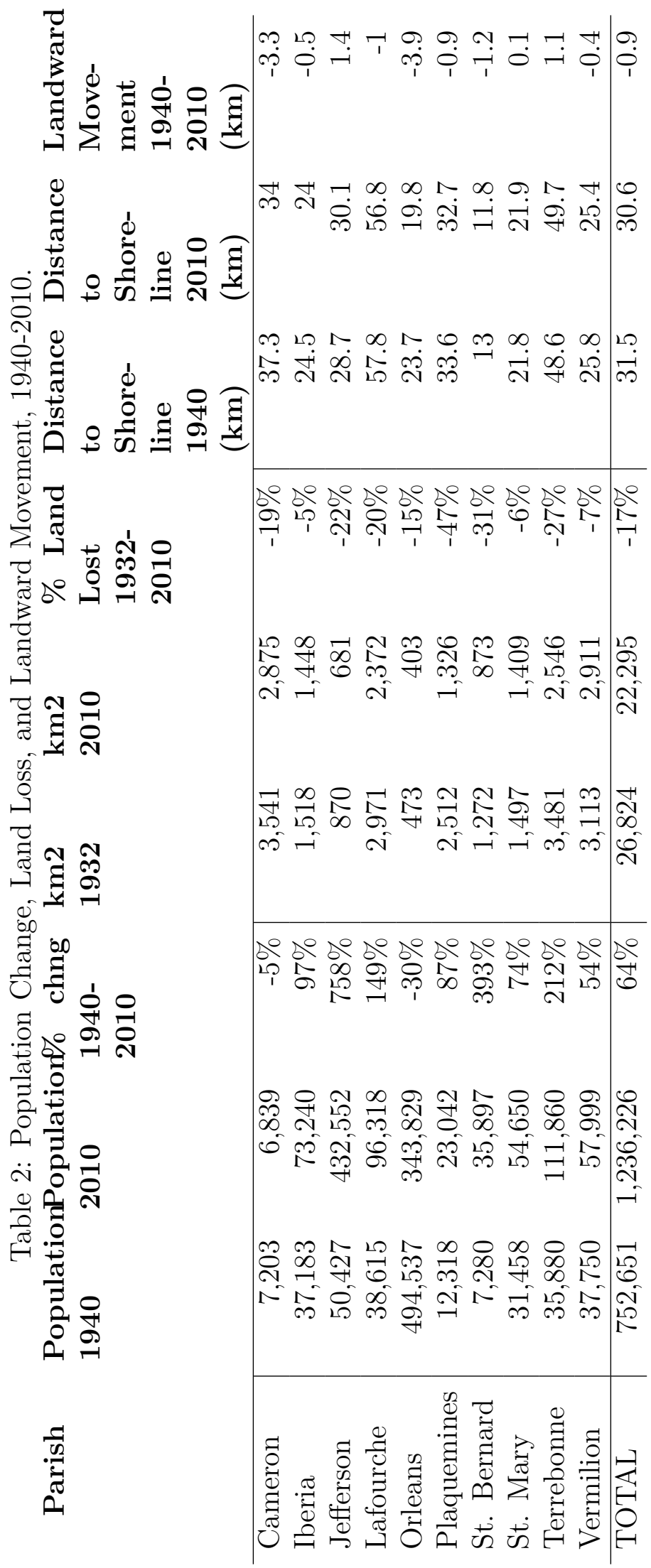




\section{References}

Bailey, Conner, Robert Gramling and Shirley B Laska. 2014. Complexities of resilience: adaptation and change within human communities of coastal Louisiana. In Perspectives on the Restoration of the Mississippi Delta. Springer pp. 125-140.

Bardsley, Douglas K and Graeme J Hugo. 2010. "Migration and climate change: examining thresholds of change to guide effective adaptation decision-making." Population and Environment 32(2-3):238-262.

Barras, John, Shelly Beville, Del Britsch, Stephen Hartley, Suzanne Hawes, James Johnston, Paul Kemp, Quin Kinler, Antonio Martucci, Jon Porthouse et al. 2003. Historical and projected coastal Louisiana land changes: 1978-2050. United States Geological Survey.

Beckman, Richard J, Keith A Baggerly and Michael D McKay. 1996. "Creating synthetic baseline populations." Transportation Research Part A: Policy and Practice 30(6):415-429.

Berrang-Ford, Lea, James D. Ford and Jaclyn Paterson. 2011. "Are we adapting to climate change?" Global Environmental Change 21(1):25-33.

Black, Richard, Neil Adger, Nigel Arnell, Stefan Dercon, Andrew Geddes and David Thomas. 2011. "The effect of environmental change on human migration." Global Environmental Change 21:S3-S11.

Black, Richard, Stephen RG Bennett, Sandy M Thomas and John R Beddington. 2011. "Climate change: Migration as adaptation." Nature 478(7370):447-449.

Boesch, Donald F. 2006. "Scientific requirements for ecosystem-based management in the restoration of Chesapeake Bay and Coastal Louisiana." Ecological Engineering 26(1):6-26.

Boesch, Donald F, Michael N Josselyn, Ashish J Mehta, James T Morris, William K Nuttle, Charles A Simenstad and Donald JP Swift. 1994. "Scientific assessment of coastal wetland loss, restoration and management in Louisiana." Journal of Coastal Research pp. i-103.

Burley, David, Pam Jenkins, Shirley Laska and Traber Davis. 2007. "Place attachment and environmental change in coastal Louisiana." Organization \& Environment 20(3):347-366.

Choupani, Abdoul-Ahad and Amir Reza Mamdoohi. 2016. "Population synthesis using iterative proportional fitting (IPF): A review and future research." Transportation Research Procedia 17:223-233.

Connell, John. 1990. "The Carteret Islands: precedents of the Greenhouse effect." Geography $75(2): 152-154$.

Connell, John. 2016. "Last days in the Carteret Islands? Climate change, livelihoods and migration on coral atolls." Asia Pacific Viewpoint 57(1):3-15.

Couvillion, Brady R, Holly Beck, Donald Schoolmaster and Michelle Fischer. 2017. Land area change in coastal Louisiana (1932 to 2016). Technical report Reston, VA: .

URL: http://pubs.er.usgs.gov/publication/sim3381 
Couvillion, Brady R, John A Barras, Gregory D Steyer, William Sleavin, Michelle Fischer, Holly Beck, Nadine Trahan, Brad Griffin and David Heckman. 2011. "Land area change in coastal Louisiana from 1932 to 2010.”.

Craig, NJ, RE Turner and John W Day. 1979. "Land loss in coastal Louisiana (USA)." Environmental Management 3(2):133-144.

Cromley, RG, AY Ebenstein and DM Hanink. 2009. "Estimating components of population change from census data for incongruent spatial/temporal units and attributes." Journal of Spatial Science 54(2):89-99.

Curtis, Katherine and Annemarie Schneider. 2011. "Understanding the demographic implications of climate change: estimates of localized population predictions under future scenarios of sea-level rise." Population and Environment 33:28-54.

Curtis, Katherine J, Elizabeth Fussell and Jack DeWaard. 2015. "Recovery migration after Hurricanes Katrina and Rita: Spatial concentration and intensification in the migration system." Demography 52(4):1269-1293.

Dehring, Carolyn A. 2006. "Building codes and land values in high hazard areas." Land Economics 82(4):513-528.

Deming, W Edwards and Frederick F Stephan. 1940. "On a least squares adjustment of a sampled frequency table when the expected marginal totals are known." The Annals of Mathematical Statistics 11(4):427-444.

Döös, Bo R. 1997. "Can large-scale environmental migrations be predicted?" Global Environmental Change 7(1):41-61.

Findlay, Allan M. 2011. "Migrant destinations in an era of environmental change." Global Environmental Change 21:S50-S58.

Fox, Douglas. 2007. "Back to the no-analog future?" Science 316(5826):823-825.

Gagliano, Sherwood M, Klaus J Meyer-Arendt and Karen M Wicker. 1981. "Land loss in the Mississippi River deltaic plain.".

Gibbons, Sheila J Arenstam and Robert J Nicholls. 2006. "Island abandonment and sea-level rise: An historical analog from the Chesapeake Bay, USA." Global Environmental Change $16(1): 40-47$.

Gornitz, V. 2013. Rising Seas: Past, Present, Future. Columbia University Press.

Gutmann, Myron P and Vincenzo Field. 2010. "Katrina in historical context: environment and migration in the US." Population and environment 31(1-3):3-19.

Hammer, Roger B, Susan I Stewart, Richelle L Winkler, Volker C Radeloff and Paul R Voss. 2004. "Characterizing dynamic spatial and temporal residential density patterns from 1940-1990 across the North Central United States." Landscape and Urban Planning $69(2): 183-199$. 
Hardy, R D and M E Hauer. 2018. "Social vulnerability projections improve sea-level rise risk assessments." Applied Geography 91(2):10-20.

Hauer, Mathew E. 2017. "Migration induced by sea-level rise could reshape the US population landscape." Nature Climate Change 7:321-325.

Hauer, Mathew E, Jason M Evans and Clark R Alexander. 2015. "Sea-level rise and subcounty population projections in coastal Georgia." Population and Environment 37(1):4462.

Hauer, Mathew E, Jason M Evans and Deepak R Mishra. 2016. "Millions projected to be at risk from sea-level rise in the continental United States." Nature Climate Change 6(7):691-695.

Hino, Miyuki, Christopher B Field and Katharine J Mach. 2017. "Managed retreat as a response to natural hazard risk." Nature Climate Change 7(5):364-370.

Hori, Makiko, Mark J Schafer and David J Bowman. 2009. "Displacement dynamics in southern Louisiana after Hurricanes Katrina and Rita." Population research and policy review 28(1):45-65.

Huntington, Henry P, Eban Goodstein and Eugénie Euskirchen. 2012. "Towards a tipping point in responding to change: rising costs, fewer options for Arctic and global societies." Ambio 41(1):66-74.

IPCC. 2014. Climate Change 2014: Impacts, Adaptation, and Vulnerability. Part A: Global and Sectoral Aspects. Contribution of Working Group II to the Fifth Assessment Report of the Intergovernmental Panel on Climate Change [Field, C.B., V.R. Barros, D.J. Dokken, K.J. Mach, M.D. Mastrandrea, T.E. Bilir, M. Chatterjee, K.L. Ebi, Y.O. Estrada, R.C. Genova, B. Girma, E.S. Kissel, A.N. Levy, S. MacCracken, P.R. Mastrandrea, and L.L. White (eds.)]. Cambridge, United Kingdom and New York, NY, USA: Cambridge University Press.

Kahn, Matthew E. 2014. Climate change adaptation: lessons from urban economics. Technical report National Bureau of Economic Research.

Lutsey, Nicholas and Daniel Sperling. 2008. "America's bottom-up climate change mitigation policy." Energy Policy 36:673-685.

Lutz, Wolfgang, A. Goujon, K. Smir and W. Sanderson. 2007. Vienna yearbook of population research. Vienna, Austria: Vienna Institute of Demography.

Maldonado, Julie Koppel. 2015. "Everyday practices and symbolic forms of resistance: adapting to environmental change in coastal Louisiana." Hazards, Risks and Disasters in Society

Maldonado, Julie Koppel, Christine Shearer, Robin Bronen, Kristina Peterson and Heather Lazrus. 2013. "The impact of climate change on tribal communities in the US: displacement, relocation, and human rights." Climatic Change 120(3):601-614. 
Marcos, Marta, Ben Marzeion, Sönke Dangendorf, Aimée BA Slangen, Hindumathi Palanisamy and Luciana Fenoglio-Marc. 2017. "Internal variability versus anthropogenic forcing on sea level and its components." Surveys in Geophysics 38(1):329-348.

Martinich, Jeremy, James Neumann, Lindsay Ludwig and Lesley Jantarasami. 2013. "Risks of sea level rise to disadvantaged communities in the United States." Mitigation and Adaptation Strategies for Global Change 18(2):169-185.

McLeman, Robert A. 2011. "Settlement abandonment in the context of global environmental change." Global Environmental Change 21:S108-S120.

Mitrovica, J X, N Gomez and P U Clark. 2009. "The sea-level fingerprint of West Antarctic collapse." Science 323(5915):753.

Neumann, Barbara, Athanasios T Vafeidis, Juliane Zimmermann and Robert J Nicholls. 2015. "Future coastal population growth and exposure to sea-level rise and coastal flooding-a global assessment." PloS one 10(3):e0118571.

Nicholls, Robert J, Natasha Marinova, Jason A Lowe, Sally Brown, Pier Vellinga, Diogo De Gusmao, Jochen Hinkel and Richard SJ Tol. 2011. "Sea-level rise and its possible impacts given a 'beyond $4 \mathrm{C}$ world'in the twenty-first century." Philosophical Transactions of the Royal Society of London A: Mathematical, Physical and Engineering Sciences 369(1934):161-181.

Olea, Ricardo A and James L Coleman Jr. 2013. "A Synoptic Examination of Causes of Land Loss in Southern Louisiana as Related to the Exploitation of Subsurface Geologic Resources." Journal of Coastal Research 30(5):1025-1044.

Peltier, WR. 2004. "Global glacial isostasy and the surface of the ice-age Earth: the ICE-5G (VM2) model and GRACE." Annu. Rev. Earth Planet. Sci. 32:111-149.

Plyer, A, J Bonaguro and K Hodges. 2010. "Using administrative data to estimate population displacement and resettlement following a catastrophic US disaster." Population and Environment 31:150-175.

Rose, Amy N and Nicholas N Nagle. 2017. "Validation of spatiodemographic estimates produced through data fusion of small area census records and household microdata." Computers, Environment and Urban Systems 63:38-49.

Rowley, RJ, JC Kostelnick, D Braaten, X Li and J Meisel. 2007. "Risk of rising sea level to population and land area." Eos, Transactions American Geophysical Union 88:105.

Sastry, Narayan. 2009. "Displaced New Orleans residents in the aftermath of Hurricane Katrina: Results from a pilot survey." Organization 65 environment 22(4):395-409.

Simms, Jessica RZ. 2016. "“Why Would I Live Anyplace Else?”: Resilience, Sense of Place, and Possibilities of Migration in Coastal Louisiana." Journal of Coastal Research 33(2):408-420. 
Smit, Barry and MarkW Skinner. 2002. "Adaptation options in agriculture to climate change: a typology." Mitigation and Adaptation Strategies for Global Change 7(1):85-114.

Smith, Stanley K, Jeff Tayman and David A Swanson. 2006. State and local population projections: Methodology and analysis. Springer Science \& Business Media.

Steel, Tom. 2011. The Life and Death of St. Kilda: The moving story of a vanished island community. HarperCollins UK.

Strauss, Benjamin H, Scott Kulp and Anders Levermann. 2015. "Carbon choices determine US cities committed to futures below sea level." Proceedings of the National Academy of Sciences 112(44):13508-13513.

Swanson, David A, Alan Schlottmann and Bob Schmidt. 2010. "Forecasting the population of census tracts by age and sex: An example of the Hamilton-Perry method in action." Population Research and Policy Review 29(1):47-63.

Thiede, Brian C and David L Brown. 2013. "Hurricane Katrina: Who stayed and why?" Population Research and Policy Review 32(6):803-824.

Titus, JG, DE Hudgens, DL Trescott, M Craghan, WH Nuckols and et al. 2009. "State and Local government plant for development of most land vulnerable to rising sea level along the US Atlantic Coast." Environmental Research Letters 4.

Wong, David WS. 1992. "The reliability of using the iterative proportional fitting procedure." The Professional Geographer 44(3):340-348.

Wu, Shuang-Ye, Brent Yarnal and Ann Fisher. 2002. "Vulernability of coastal communities to sea=level rise: a case study of Cape May County, New Jersey USA." Climate Research 22:255-270.

Yusuf, Juita-Elena, Katharine Neill, Burton St John III, Ivan K Ash and Kaitrin Mahar. 2016. "The sea is rising... but not onto the policy agenda: A multiple streams approach to understanding sea level rise policies." Environment and Planning C: Government and Policy 34(2):228-243.

Zhang, Keqi, Bruce C Douglas and Stephen P Leatherman. 2004. "Global warming and coastal erosion." Climatic Change 64(1):41-58. 